\title{
Using Pine Wood Derby Cars to Introduce Mechanical Engineering to Students in a First Year General Engineering Design Course
}

\author{
David Torvi, P.Eng. \\ Associate Professor, Department of Mechanical Engineering \\ University of Saskatchewan \\ david.torvi@usask.ca
}

\begin{abstract}
In order to introduce students to mechanical engineering, a first year design laboratory was developed based on pine wood derbies that are run in various children's organizations. In these races, children and their parents design and build a car using a kit consisting of a pine block, metal axles and plastic wheels. This design exercise introduces students to several aspects of mechanical engineering, including manufacturing, aerodynamics, and material science. It also builds on courses that cover engineering drawing and report writing.
\end{abstract}

\section{Introduction}

"You might be an engineer...if you use a CAD package to design your child's Pine Wood Derby car."

Popular Engineering Joke [1]

In the College of Engineering at the University of Saskatchewan, students spend one year in general engineering, before choosing a department for the final three years of their program. In order to assist students in this choice, each department makes presentations to students describing their discipline, and providing information on their program and career paths for graduates. In their second term Introduction to Engineering II course (GE 120), students complete a series of design laboratories which introduce them to each of the disciplines [2],[3].

In order to introduce students to mechanical engineering, a first year design laboratory was developed based on pine wood derbies that are run in various children's organizations, such as Scouts and community and church groups. In these races, children and their parents design and build a car using a kit consisting of a pine block, metal axles and plastic wheels (Figure 1). Typically, there are restrictions on total mass, axle locations, and overall dimensions of the race car. In many derbies, only the axles and wheels supplied with the kit can be used.

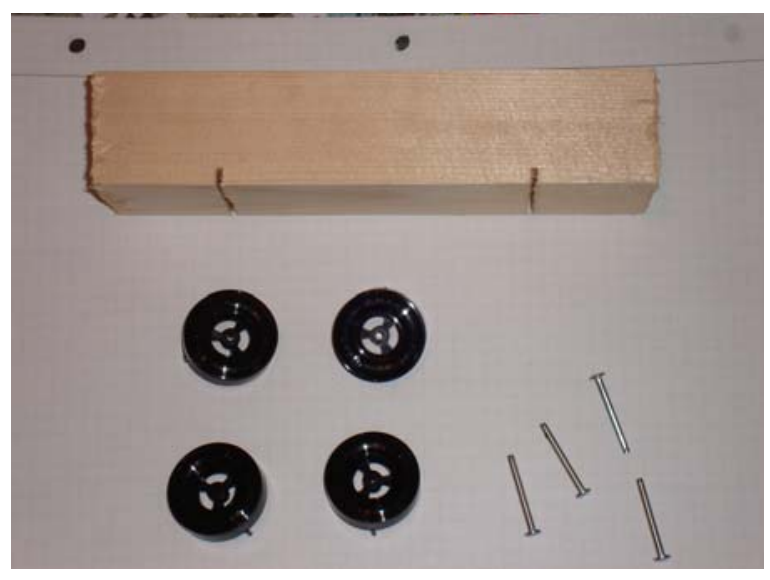

Figure 1. Pine Wood Derby Set

Races are held on a track with starting blocks, dividers to keep each car in its own lane, and in some cases an electronic timing system. Most track layouts include an initial section with a steep incline, a curved transition section and a flat section that extends to the finish line and beyond (Figure 2).

Winners of the derby are determined based on a series of heats, or in some cases, a round-robin tournament. In some groups, prizes are also awarded for design and originality. Therefore, while some cars are designed strictly on the basis of performance, children may also race vehicles that are made to look like other items, such as characters from movies and television programs or consumer products (e.g., Figure 3). 


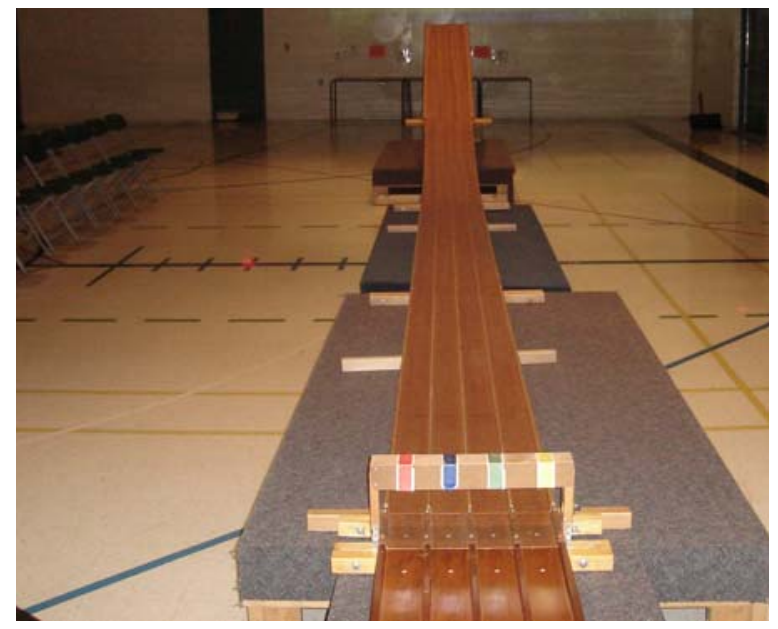

Figure 2. Pine Wood Derby Track
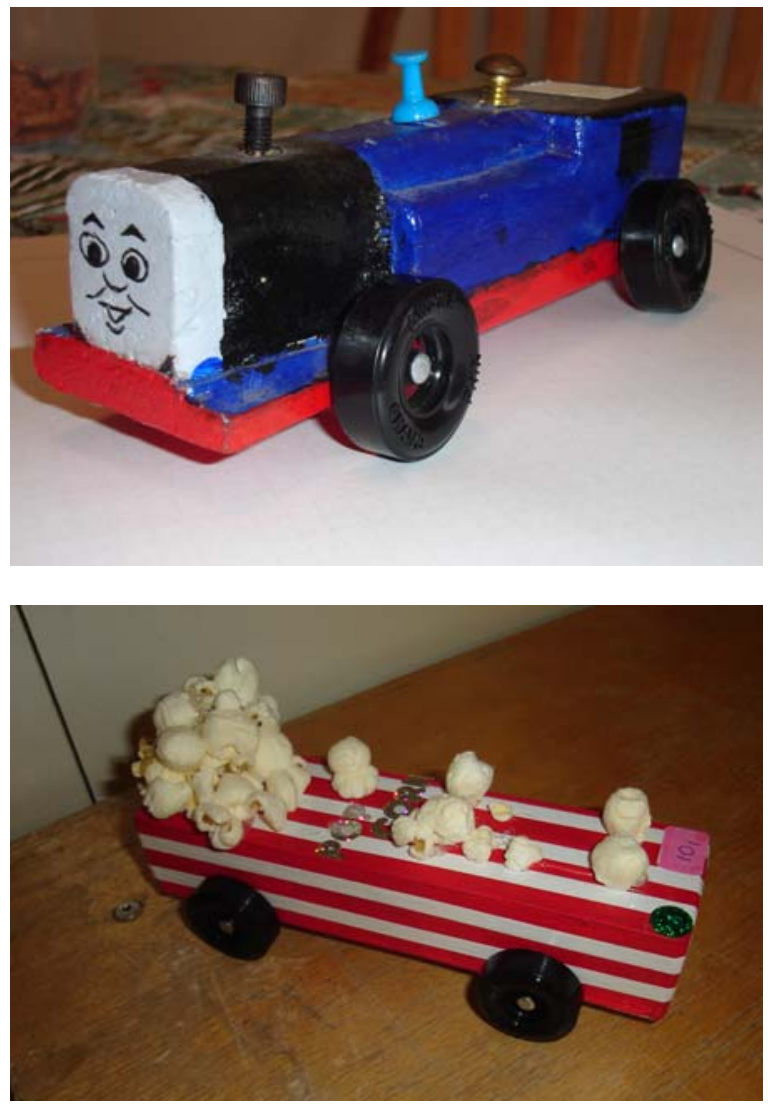

Figure 3. Examples of Pine Wood Derby Cars

A number of engineering programs have used pine wood derby races in their outreach efforts to get students interested in engineering. For example, the University of Illinois at Urbana-Champaign developed a brochure containing tips on building these cars for Scouts [4]. They also developed a three hour workshop to educate Scouts on the engineering principles behind these cars, and to help them build cars for their races. Specific engineering principles covered include friction, aerodynamics, and weight distribution and energy. The Milwaukee School of Engineering runs a weeklong program for high school students, the Rapid Prototyping (RP) Derby, a modified competition in which students design, build and test cars [5]. This program utilizes SolidWorks ${ }^{\circledR}$ and rapid prototyping equipment, and exposes students to aerodynamics, internal combustion engines, materials and other aspects of engineering.

There are a number of examples of the use of pine wood derby cars and races in engineering courses. Students in a Cornell University fourth year experimental fluid mechanics and heat transfer course (MAE 427) build and race trucks in a modified pine wood derby [6],[7]. A case study on the pine wood derby is included as a chapter in a textbook used in systems engineering courses [8]. One of the authors of this book has also published a risk analysis of these competitions [9]. Laboratory activities in a dynamics class in Purdue University's Mechanical Engineering Technology program (MET 213) include a pine wood derby, and an analysis of data from pine wood derby races [10]. One of the instructors in this course has also published a description of a photoresistor timing system that can be used in these races [11].

Pine wood derby cars and races have also been used in capstone engineering design projects, such as the design of a timing system for races [12]. Students in engineering and other disciplines have examined the physics of these races [13] including the effect of weight distribution on the performance of cars [14]. There are also a large number of on-line sources of information on these races. Many of these are commercial web sites which sell supplies, and books of tips on building a winning race car (e.g., [15]). Other sites discuss the physics of these races (e.g., [16]). The joke that opens this paper describes an engineer as someone uses a CAD package to design their child's pine wood derby car. An article in a Pro/Engineer ${ }^{\circledR}$ magazine describes a race car entered in a modified derby that was designed using Pro/Engineer ${ }^{\circledR}$ software, and partially manufactured using rapid prototyping technology [17].

This paper describes a pine wood derby design challenge given to first year students, and discusses how this exercise helps to introduce students to mechanical engineering. Engineering analyses used by students to predict the performance of their designs are described. Possible modifications to this 
laboratory, which would allow students to gain more hands-on experience in either this class, or upper-year courses, are also discussed.

\section{GE 120 Pine Wood Derby Design Laboratory}

Most examples of pine wood derby design problems used in engineering schools are assignments that groups of students work on over a relatively long period of time. The design laboratories in GE 120 assume that students will work on each disciplinebased design challenge during one three hour laboratory period and for several hours outside of class [2]. Therefore, because of time constraints this assignment is primarily a paper-based design. However, as will be noted later in the paper, this exercise can easily be extended to a more hands-on experience where students build and race their cars, such as in other engineering programs.

The design exercise given to the students is as follows. A local children's club is holding their annual Pine Wood Derby. This year the club also decides to put on an open category. Most of the rules for the open category, such as the restrictions placed on the dimensions and the mass of the car, are the same as the regular derby. The maximum length, width and height of the car are $178 \mathrm{~mm}$ (7 in.), $70 \mathrm{~mm}$ (2 3/4 in.) and $76 \mathrm{~mm}$ (3 in.), respectively. The maximum mass of the car is $150 \mathrm{~g}$ ( $5 \mathrm{oz}$.). Wheel bearings, bushings, washers and springs are prohibited. There should be a minimum of $1 \mathrm{~cm}$ clearance between the track and the bottom of the car, and the axles must be $100 \mathrm{~mm}$ apart. No starting devices are permitted.

The main difference between the two competitions is what materials that can be used to construct the race car. In the regular derby, only the wood blocks, metal axles and plastic wheels supplied with the car are permitted. Other materials may be used for construction in the open category. However, in order to make the race affordable for all participants, the club sets a maximum limit of $\$ 20$ for materials. Children can also decide enter either competition using the standard pine car kits (pine block, axles and wheels), which are available for $\$ 5$. Parents are permitted to do some of the cutting of wood and other materials for their children, but the child should be involved in the assembly of the car.

Students are asked to design a car for a child to enter the open competition. It should be possible for a 10 year old child to build their design, with minimal supervision by their parents. The deliverables for this project are: a set of shop drawings for the racing car using standard orthographic views; an isometric sketch or drawing of the car; and a list of materials, including costs. Students must also submit a short report (maximum 1000 words) that compares the expected performance of their design with the performance of a car designed for last year's race using a standard pine car kit (Figure 4). Students are also asked to hand in a cover letter, which highlights the main aspects that make their design unique. Besides the design report and engineering drawings, students are also required to keep their design calculations in their course logbook.
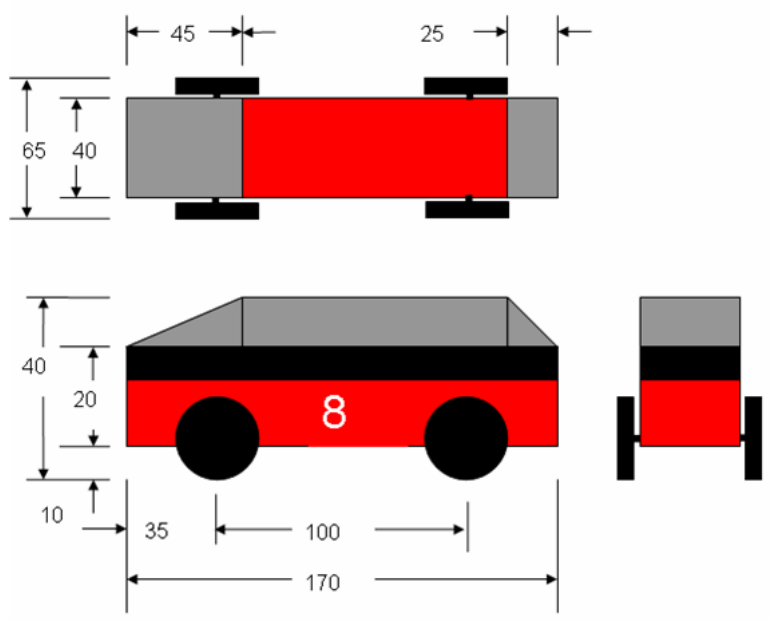

Figure 4. Previous Pine Wood Car Design

Students are provided with information on the contents of the $\$ 5$ car kit, including the dimensions of the block, the density of the pine, the diameter and width of the plastic tires, and the mass of the wheels and axles. Students are asked to follow the engineering method that the have been taught in their two Introduction to Engineering courses (GE 110 and 120) when developing their design. They are encouraged to develop a list of design criteria, such as cost and ease of manufacturing, and a list of constraints, such as the maximum dimensions and mass for the vehicle, before beginning their design.

In their reports, students are asked to discuss the problem, design objectives, criteria used to select their final design, and provide an engineering analysis of their design. While students may not have covered the theory necessary to analyze all aspects of the design of their car, they are asked to at least discuss the types of analysis that should be done when designing the car. There are also general guidelines they must follow for this and their other GE 120 design reports. 
As noted earlier, there are a surprisingly large number of different on-line sources that provide information on how to design a high performance pine wood car. The students are told that these sources may be useful as they design their car. However, the expectation in this lab is that they should be able to quantify how at least some of the aspects of their design will improve performance by using engineering calculations. One suggestion is that students can estimate how the new design will decrease the time required to complete the race.

There may also be some aspects of the design that would be more easily evaluated using testing, rather than calculations. One of the objectives of this exercise is to familiarize students with the Department of Mechanical Engineering's facilities. Therefore, students are asked to use information from the Mechanical Engineering discipline presentations and the College website to describe any equipment within the department that could be used to test their race car design.

\section{Engineering Analysis of Pine Wood Derby Cars}

Students were asked to complete an engineering analysis of the vehicle dynamics of the pine wood derby cars, using the theory that they had learned to date in their engineering programs. At this point the students will have completed a statics course and their first introduction to engineering course. At the time of this laboratory, the students will be taking a dynamics course. Based on what they have taken so far in their first year courses, students are provided with guidance on how to do a simple analysis of the vehicle dynamics of their race car.

A simplified track layout is used for the analysis (Figure 5). The students were encouraged to split the problem into two parts; the downhill portion from 1 to 2 and the level portion from 2 to 3 . As this point the students are still early in their dynamics course. Therefore, they take a particle dynamics approach, and can do their analysis based on force-acceleration, or an energy analysis. They are asked to consider losses due to air resistance, rolling resistance and other factors, such as the extra distance a car would need to cover if the wheels are not aligned.

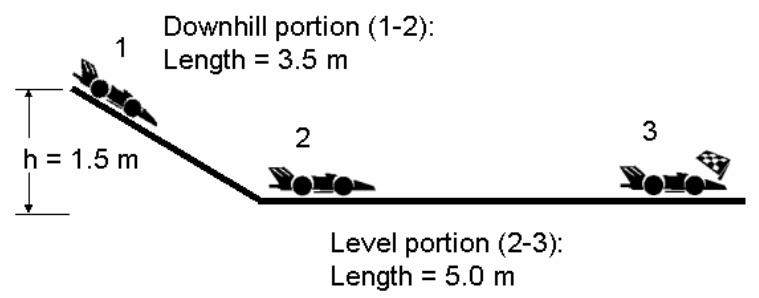

Figure 5. Simplified Pine Wood Derby Race Track Layout for Design Lab

As students will not have taken courses in aerodynamics, or other areas of Mechanical Engineering needed to do a complete analysis, they were given simple equations they could use to investigate the effects of certain parameters on the performance of the car. For example, they were given the equation for the drag force on the car:

$$
F_{D}=\frac{1}{2} \rho C_{D} A_{f} V^{2}
$$

where $\rho$ is the air density, $C_{D}$ is the drag coefficient, $A_{f}$ is the frontal area of the car, and $V$ is the velocity of the car. Students were asked to do a search for data on the value of drag coefficient for various shapes in order to determine how much of an effect this parameter would have on the expected time for the car to finish the race.

One important part of the analysis was to demonstrate the magnitude of the effects of various losses on predicted race performance. For example, it was estimated that for a particular design, drag and rolling resistance might increase the time required to complete the race by $0.3 \mathrm{~s}$. At the estimated velocity at point 3 , this increase in time to complete the race corresponds to a difference in distance travelled of about $1.2 \mathrm{~m}$. This distance is approximately seven times the maximum permitted length of the race car. As many races are decided by less than a car length, this calculation helps to demonstrate to the students the importance of reducing drag and other losses.

\section{Discussion}

This exercise introduces students to a broad range of topics covered in the mechanical engineering program. For example, as students can use any material to build their car, material selection criteria are introduced. Costs must be compared to the $\$ 20$ maximum. As the car must be built by a 10 year old child, with minimal assistance, there are constraints as to the types of equipment that can be used to manufacture the vehicle. 
Aerodynamics is also introduced, along with dynamics and aspects of machine design. By requiring students to develop a list of performance tests for their cars, they are also introduced to testing in general, and to the Department's facilities. The project also provides students with additional experience in engineering drawing and report writing. One advantage of this particular design problem is that many students are already familiar with pine wood derbies, or similar competitions.

While a simple analysis of this problem can be done by second-term first year engineering students, the problem can easily be expanded to students in upper years, such as has been done at other engineering schools. If more time is available, students can build their own cars, using facilities in the engineering school, providing manufacturing experience. As mentioned in the introduction, one school uses rapid prototyping technology in an outreach program based on pine wood derby cars [5]. This approach may also be appropriate in an upper year class as well, in order to expose the students to this, or similar technology, such as computer assisted manufacturing equipment.

During their analysis, students select a drag coefficient based on data from handbooks or other sources. In an upper year class, students could measure drag forces on their car. This approach is used at other schools, where students test various shapes of race cars to learn about lift, drag and other concepts in aerodynamics [18]. There are a number of resources that can be used in upper-year courses for students who wish to study the vehicle dynamics in more detail (e.g., [19], [20]).

If students do build and race their own cars, predictions made using the student's analysis could be compared to actual race performance. This exercise would provide further opportunities to learn about measurements, sensors and possibly control systems. As pine wood derbies are run annually in many children's clubs, schools can partner with these organizations to avoid having to build their own tracks. This may also represent an outreach opportunity for engineering schools, such as the program at the University of Illinois [4].

In the current arrangement, it is difficult to provide an opportunity for first-year students to build and race cars. However, in order to provide an opportunity to observe how different factors affect race performance, several variations on this laboratory could be run. Prebuilt race cars of various shapes could be raced. One disadvantage of this approach is that it is not as open- ended as the current design challenge. It also does not provide the same opportunities to learn about the manufacturing process. Another option is to replace the pine wood derby cars with cars that the students build out of LEGO blocks. This would allow students to race their cars and to compare the effects of various design features on performance, such as shape, mass, size of wheels and wheelbase. This activity is already used in some science centres to demonstrate some of these principles to young children (e.g., [21]; the difference here is that students should be able to explain the reasons for the differences in performance, and in some cases to quantify the expected differences.

\section{Conclusions}

This paper describes a design laboratory that can be used to introduce first year engineering students to various aspects of mechanical engineering, such as manufacturing, material science, and aerodynamics. While intended for use as a relatively short design project for first year students, it can be easily modified to a longer project for upper year students, as has been done in other engineering schools. It also can be used as part of outreach efforts to help attract primary and secondary school students to engineering.

\section{Acknowledgements}

The author would like to thank Profs. Barry Hertz, Tim Muench, Terry Fonstad, Jian Peng and David Sumner of the College of Engineering at the University of Saskatchewan for their suggestions and technical advice.

\section{References}

[1] Integrated Technical Solutions, "You might be an engineer if...”, November, 1999. [Online]. Available: www.teamits.com/connection/humor/engineertest.html. [Accessed: June 12, 2007].

[2] T.C. Muench, "Successful methods for developing introductory design labs as preparation for upper year discipline selection and multi-disciplinary design", in Proceedings, $2^{\text {nd }}$ International CDEN Conference, 2005.

[3] T.C. Muench and T. Fonstad, "Designing evaluation into open-ended design labs” in Proceedings, $2^{\text {nd }}$ International CDEN Conference, 2005.

[4] T.A. Solzak and A.A. Polycarpou, "Engineering outreach to cub scouts with hands-on activities pertaining to the 
pinewood derby car race”, International Journal of Engineering Education, vol. 22, pp. 1077-1096, 2006.

[5] J.C. Musto, W.E. Howard and S. Rather, "The RP derby: a design/build/test experience for high school students”, in Proceedings, ASEE Annual Conference, 2000. [Online]. Available: www.asee.org/acPapers/20536.pdf. [Accessed June 11, 2007].

[6] "Be a big wig, design a big rig”, Cornell Engineering Magazine, Spring, 1999. [Online]. Available: www.engineering.cornell.edu/news/engineeringmagazine. [Accessed June 11, 2007].

[7] “A little competition”, Cornell Chronicle, December 13, 2001. [Online]. Available: www.news.cornell.edu/ Chronicle/Chronicle.shtml. [Accessed June 11, 2007].

[8] W.L. Chapman, A.T. Bahill and A.W. Wymore, Engineering Modeling and Design, Boca Raton: CRC Press, 1992.

[9] A.T. Bahill and W.J. Karnavas, "Risk analysis of a pinewood derby: a case study”, Systems Engineering, vol. 3, pp. 143-155, 2000.

[10] M. French, "MET 213 - Dynamics”, Spring, 2006. [Online]. Available: www2.tech.purdue.edu/met/ courses/met213/. [Accessed June 11, 2007].

[11] R.M. French, "My favorite experiment series part 3: measuring performance of a toy car under force of gravity”, Experimental Techniques, vol. 29, no. 5, pp. 44-46, September/October, 2005.

[12] "Watson seniors unveil capstone design projects", Inside Binghamton University, May 8, 2003. [Online]. Available: http://inside.binghamton.edu/. [Accessed June 11, 2007].

[13] S. Dunn, J. Hayes, R. Woofter and L. Mills, "The physics of the cub scout pinewood derby”, presented at the $14^{\text {th }}$ Annual Scientific Research Poster Session, The College of Charleston School of Science and Mathematics, 2002. [Online]. Available: www.cofc.edu/ physics/poster_02/abstracts.html. [Accessed June 11, 2007].

[14] M. Devine, "The physics of the pinewood derby". [Online]. Available: www-cs-students.stanford.edu/ mdevine/. [Accessed June 11, 2007].

[15] “ABC pinewood car”. [Online]. Available: www.abcpinewood-derby.com. [Accessed June 13, 2007].

[16] "The physics of the pinewood derby and gravity-driven race cars”, June 11, 2007. [Online]. Available: www.pinewoodderbyphysics.com. [Accessed June 11, 2007].
[17] E. Goates, "Going Pro/extreme at the pinewood derby: designing a racecar with verve”, Pro/E: The Magazine, vol. 11, no. 4, pp. 8-10, July/August, 2003. [Online]. Available: www.synthx.com/articles/ProEDerby.pdf. [Accessed June 11, 2007].

[18] A.M. Anderson and J. Losaw, "Using race car aerodynamics to teach mechanical engineering students about fluid mechanics”, in Proceedings, ASEE Annual Conference, 2002. [Online]. Available: www.asee.org/ acPapers/2002-885_Final.pdf. [Accessed June 13, 2007].

[19] W.H. Hucho, “Aerodynamics of road vehicles”, Annual Review of Fluid Mechanics, vol. 5, pp. 485-537, 1993.

[20] J. Katz, “Aerodynamics of race cars”, Annual Review of Fluid Mechanics, vol. 38, pp. 27-63, 2006.

[21] "Exhibits and shows: Eureka!” Telus World of Science Calgary. [Online]. Available: www.calgaryscience.ca/ exhibits/exhibits/eureka. [Accessed June 13, 2007]. 